\title{
PRECISAMOS FALAR SOBRE CARREIRA E A SUA ESTRUTURAÇÃO PARA ESTUDANTES DE ADMINISTRAÇÃO
}

\section{IT IS NECESSARY TO TALK ABOUT THE CAREER AND ITS STRUCTURING FOR STUDENTS OF MANAGEMENT}

\section{D0I: http://dx.doi.org/10.21714/raunp.v10i2.1783}

\section{Lorena dos Santos Pattas}

Universidade do Estado da Bahia. E-mail: lorenapattas@gmail.com

\section{Tania Moura Benevides}

Universidade do Estado da Bahia. E-mail: taniamoura2511@gmail.com

Envio em: Dezembro de 2017

Aceite em: Abril de 2018

\section{RESUMO}

0 presente artigo socializa os resultados de uma pesquisa realizada com os discentes de Administração do Departamento de Ciências Humanas-I da Universidade do Estado da Bahia (DCH-I/UNEB), matriculados em 2017.1. A investigação teve por objetivo geral verificar a existência do planejamento de carreira, destacando os fatores que influenciam os discentes do DCH-I/UNEB, do curso de Administração, a optarem pela carreira de Administrador. Em relação ao percurso metodológico, esse trabalho partiu de uma revisão de literatura e pesquisa documental para a definição das categorias de análise, que foram: Administração enquanto escolha de carreira, carreira e planejamento de carreira. Adotou-se para análise e estruturação do estudo a abordagem qualitativa e para o levantamento de dados primários, na fase de pesquisa de campo, um questionário com questões abertas e fechadas como instrumento de coleta de dados. Os dados coletados foram tabulados pelo Sphinx 2000 e, posteriormente, analisados à luz da análise de conteúdo. 0s resultados apontam que a maioria dos discentes [95,3\%] nunca realizou um planejamento individual de suas carreiras apesar da importância que atribuem a esta inciativa. Portanto, conclui-se que 0 tema precisa ganhar destaque na grade do curso ou em atividades complementares que o possa contemplar.

Palavras-chave: Administração. Escolha de Carreira. Planejamento de Carreira.

\section{ABSTRACT}

The present paper socializes the results of a research done with the students of Administration of the Department of Human Sciences-I of the State University of Bahia (DCH-I/UNEB), registered in 2017.1. The general objective of the investigation was to verify the existence of the career planning, emphasizing the factors that influence the students of the DCH-I / UNEB, of the graduation in Management, to opt for the career of Manager. Regarding the methodology, this work started with a review of literature and documentary research to define the categories of analysis, which were: Management, career choice, career and career planning. The qualitative approach and for the primary data collection were adopted for the analysis and structuring of the study, in the field research phase, a questionnaire with open and closed questions as a data collection instrument. The data collected were tabulated by Sphinx 2000 and later analyzed in light of content analysis. The results show that most of the students [95.3\%] never made individual planning of their careers despite the importance they attribute to this initiative. Therefore, it is concluded that the theme needs to be highlighted in the course grade or in complementary activities that can contemplate it.

Key-words: Management. Career choice. Career Planning. 


\section{INTRODUÇÃO}

Por seu caráter que dialoga com várias expertises e a oferta de múltiplas áreas de atuação no mercado de trabalho, os cursos de Administração possuem ampla procura, sendo o curso superior mais ofertado no Brasil em Instituições de Ensino Superior (IES) públicas e privadas. O curso ocupa o segundo lugar no ranking de alunos matriculados (766.859) e possui o maior número de concluintes (124.986) segundo o Instituto Nacional de Estudos e Pesquisas Educacionais Anísio Teixeira (INEP/MEC, 2015), levando a uma significativa e crescente oferta de profissionais no mercado de trabalho. É importante estudar essa realidade para entender quais fatores influenciam os estudantes a escolherem essa graduação, entendendo também a dinâmica de planejamento de carreira dos administradores, já que, segundo Bertero (2006), a maioria dos matriculados em cursos de graduação de Administração, no país, tem pouca consciência do que seja uma carreira plena de Administrador.

De modo geral, dentre os vários objetivos dos cursos de Administração, um que merece destaque para este estudo é a formação de profissionais capazes de decidir sobre planejamento, organização, comando, coordenação e controle. $\mathrm{O}$ aprendizado sobre essas cinco decisões, adquirido durante o curso de graduação, é responsável por instrumentalizar os estudantes para atuarem no mercado de trabalho, em qualquer uma das múltiplas áreas que a Administração lhes oferece. Para além dessa perspectiva, este aprendizado também assume um papel importante na vida particular de cada estudante, sobretudo, quando o assunto é carreira que, por seu lado, tende a perpassar por todas as decisões mencionadas anteriormente.

Pelo exposto, o estudo se propõe a investigar a seguinte questão: Quais fatores influenciam os discentes do curso de Administração do DCH-I/ UNEB em relação à estruturação das suas carreiras? A fim de responder a tal questionamento o trabalho tem por objetivo geral verificar a existência do planejamento de carreira, destacando os fatores que influenciam os discentes do Departamento de Ciências Humanas-I da Universidade do Estada da Bahia (DCH-I/UNEB), do curso de Administração, a optarem pela carreira de Administrador. Para tanto, foram estabelecidos os seguintes objeti- vos específicos, a saber: a) caracterizar o curso de Administração do DCH-I/UNEB; b) caracterizar o perfil socioeconômico dos discentes do curso de Administração do DCH-I/UNEB matriculados em 2017.1; c) identificar os fatores que influenciaram a escolha do curso Administração; d) analisar a percepção dos discentes em relação ao planejamento de carreira, incluindo o uso de ferramentas para tal.

$O$ estudo torna-se relevante na medida em que leva à reflexão as dimensões, escolha e planejamento de carreira, no âmbito da Administração, buscando contribuir para análise e ampliação desse conhecimento que servirá para o corpo docente e discente, os quais compõem a Universidade, que se constitui em um espaço formal de educação e formação.

Estruturalmente, além dessa introdução que versa sobre a apresentação do contexto do problema e dos objetivos da pesquisa, este artigo possui quatro seções. A segunda seção abriga o referencial teórico, ancorado nos conceitos-chaves sobre escolha e estruturação da carreira de Administrador; a terceira traz o percurso metodológico utilizado para a elaboração da pesquisa; a seguir, apresentam-se os resultados da pesquisa de campo; finaliza-se com as considerações correspondentes aos principais resultados e discute-se as possíveis linhas de continuidade ao artigo.

\section{A ADMINISTRAÇÃO COMO CARREIRA NO BRASIL}

A profissão de Administrador foi regularizada no Brasil em 9 de setembro de 1965, com a implantação da Lei $n^{\circ}$. 4.769. A demanda por profissionais de Administração está diretamente relacionada ao processo de desenvolvimento do Brasil, sobretudo, a partir da década de quarenta, período no qual a sociedade estava passando de um estágio agrário para a industrialização. Segundo Covre (1982), o número crescente de Administradores advém das necessidades do processo econômico brasileiro que vem se caracterizando pela concentração econômica, acentuada após 1964, favorecendo o desenvolvimento de grandes empresas que, uma vez mais complexas.

Existem muitos conflitos atrelados à escolha profissional, sobretudo, quando se trata da escolha pelo curso de Administração, ofertado por uma IES. Por sua origem no Brasil, ora apresentada, a 
Administração se constitui em um campo de conhecimento que dialoga com distintos saberes. Portanto, trata-se de uma área de interface, indo além de uma ótica interdisciplinar, na medida em que essa abordagem epistemológica ainda se centra na disciplina, em uma linha tênue que separa e delimita os conhecimentos. Por esse motivo, possui problemas de identidade pois apresenta muitas definições, ora considerada como uma ciência, arte, tecnologia, fenômeno político e até mesmo como aquilo que os gerentes fazem (AKTOUF, 2005; BATISTA-DOS-SANTOS; OLIVEIRA, 2015).

A definição de Administração é muito difícil de ser apresentada. Normalmente, cada autor a aborda sob um aspecto diferente, portando, não permite a formação de uma filosofia única (KWASNICKA, 1980). No entanto, alguns autores definiram-na como um processo de trabalhar com pessoas e recursos para realizar objetivos organizacionais, no qual deve-se planejar, organizar, comandar, coordenar e controlar (BATEMAN; SNELL,1998; MORGAN, 2007 apud GURGEL 2013).

Sendo assim, espera-se que os indivíduos que pretendem ingressar na graduação de Administração, de qualquer IES, apresentem, mesmo que embrionariamente, conhecimento sobre as temáticas que envolvem o curso e as distintas áreas de atuação de um Administrador. Além disso, devem conhecer quais são as Competências e Habilidades $(\mathrm{C} \& \mathrm{H})$ estabelecidas pela Resolução $\mathrm{n}^{\circ} 4$, de 13 de julho de 2005 do Ministério da Educação (MEC) que diz respeito às Diretrizes Curriculares Nacionais do Curso de Graduação em Administração de Empresas e pelo Conselho Federal de Administração (CFA), as quais, são demandadas dos Administradores e devem, também, ser desenvolvidas pelos alunos ao longo do curso, afirmando o papel das IES no que diz respeito a contemplação dessas $\mathrm{C} \& \mathrm{H}$, nos seus projetos pedagógicos dos cursos de Administração.

Essa compreensão é de suma importância para que esses indivíduos possam avaliar a compatibilidade entre eles e a carreira escolhida. A compatibilidade, segundo Hall (1976 apud DUTRA, 2002), pode ser explicada através de quatro características individuais: interesse, identidade, personalidade e experiência social. Desse modo, pode ser relacionada com o primeiro e segundo estágios de carreira descritos por Snell e Bohlander (2009) como os estágios nos quais os indivíduos desenvolvem a autoimagem ocupacional, avaliam as ocupações alternativas, desenvolvem a escolha da ocupação inicial e perseguem a educação necessária. Isto é, trata-se da preparação para o trabalho e, normalmente, se estende até os vinte e cinco anos. Apresenta-se, no quadro 01, uma comparação entre as principais $\mathrm{C} \& \mathrm{H}$ estabelecidas pelos órgãos apresentados anteriormente e que devem ser levadas em consideração pelos indivíduos que pretendem estudar Administração. Foram estabelecidas 14 (catorze) dimensões com base nas $\mathrm{C} \& \mathrm{H}$ apresentadas pelo MEC e CFA. 
QUADRO 01 - COMPARAÇÃO ENTRE AS COMPETÊNCIAS E HABILIDADES DOS ADMINISTRADORES DESCRITAS PELO MEC E CFA

\begin{tabular}{|c|c|c|}
\hline DIMENSÕES & MEC & CFA \\
\hline Ética & Ética e adaptação & Comportamento ético \\
\hline Solução de Problemas & Reconhecer e definir problemas & $\begin{array}{l}\text { Identificar problemas, formular e implantar } \\
\text { soluções }\end{array}$ \\
\hline Raciocínio Lógico & Raciocínio lógico, crítico e analítico & Raciocínio lógico, crítico e analítico \\
\hline Tomada de decisão & Tomada de decisão & Planejamento, organização, direção e controle \\
\hline Adaptação & $\begin{array}{l}\text { Iniciativa, determinação, vontade } \\
\text { de aprender, abertura a mudanças }\end{array}$ & Adaptação à transformação \\
\hline Conhecimentos Estratégicos & Pensamento estratégico & $\begin{array}{l}\text { Conhecimentos específicos para administração } \\
\text { estratégica, finanças/orçamentária e a } \\
\text { motivação de pessoas/equipes }\end{array}$ \\
\hline $\begin{array}{l}\text { Projetos } \\
\text { [Elaboração e Gestão] }\end{array}$ & $\begin{array}{l}\text { Capacidade de elaborar, } \\
\text { implementar e consolidar projetos }\end{array}$ & - \\
\hline Criatividade e Inovação & - & Criatividade e inovação \\
\hline Profissionalismo & - & Comprometimento e Profissionalismo \\
\hline Comunicação e Negociação & Comunicação e negociação & - \\
\hline $\begin{array}{l}\text { Posicionamento Gerencial/ } \\
\text { Liderança }\end{array}$ & $\begin{array}{l}\text { Refletir e atuar sobre a produção, } \\
\text { diante de uma função gerencial }\end{array}$ & Preparo para liderança \\
\hline Formação em Consultoria & $\begin{array}{l}\text { Realizar consultoria em gestão e } \\
\text { Administração }\end{array}$ & - \\
\hline $\begin{array}{l}\text { Relacionamento } \\
\text { Interpessoal }\end{array}$ & - & Relacionamento interpessoal \\
\hline Visão Sistêmica & - & Visão do todo \\
\hline
\end{tabular}

Fonte: Elaboração própria a partir de dados do MEC (2005) e CFA (2011;2015).

Uma pesquisa nacional realizada pelo CFA em 2011 com 17.982 respondentes apontou que os fatores que mais influenciaram a escolha pelo curso de Administração foram, com $25,41 \%$ e $21,29 \%$ de ocorrências, respectivamente: a formação generalista e abrangente e a existência de um amplo mercado de trabalho. Ao passo que, a categoria que representava a escolha do curso derivada de um projeto de carreira estabelecido, não obteve porcentagem significativa, ficando assim com $0 \%$. Ao analisar a Pesquisa Nacio- nal do CFA de 2015 que abordou a mesma temática, observou-se que esse comportamento se repetiu, ou seja, de 20.576 respondentes, não foi possível computar respostas em relação a escolha pelo curso de Administração derivada de um projeto de carreira.

A estruturação da carreira inicia e se desenvolve a partir do momento em que o indivíduo faz a sua escolha profissional, neste caso, a escolha pelo curso de graduação, podendo esta seleção estar contida ou não no planejamento de carreira. 


\section{ESTRUTURAÇÃO DA CARREIRA:} CONCEITOS, FERRAMENTAS E ETAPAS

Para melhor compreensão da importância do planejamento de carreira, faz-se necessária uma breve exposição do conceito de carreira. Nesse momento, cabe ressaltar que este artigo não tem intenção de levar em consideração a perspectiva empresarial de carreira e sim, analisá-la sob a ótica individual que engloba o entendimento e a avaliação da experiência profissional por parte do indivíduo. Ou seja, aborda a carreira interna que é vinculada à maneira com a qual o indivíduo planeja e avalia seu desempenho profissional e a importância que confere à sua carreira. Assim como a Administração, carreira é uma palavra de difícil definição já que se trata de um termo bastante utilizado e ao qual se agregam vários significados (DUTRA, 2002). A seguir, no quadro 02, apresenta-se uma breve evolução dos conceitos de carreira, de acordo com alguns autores.

QUADRO 02- EVOLUÇÃO DOS CONCEITOS DE CARREIRA

\begin{tabular}{|l|l|}
\hline AUTORES & CONCEITO \\
\hline Hall (1976) & $\begin{array}{l}\text { É uma sequência de atitudes e comportamentos, associadas com experiências e } \\
\text { atividades relacionadas ao trabalho, durante o período de vida de uma pessoa. }\end{array}$ \\
\hline Van Maanen (1977) & $\begin{array}{l}\text { Um caminho estruturado e organizado no tempo e no espaço que pode ser } \\
\text { percorrido. }\end{array}$ \\
\hline London e Stumph (1982) & $\begin{array}{l}\text { Uma sequência de posições ocupadas e de trabalhos realizados durante a vida } \\
\text { de uma pessoa que envolve uma série de estágios e a ocorrência de transições } \\
\text { que refletem necessidades, motivos e aspirações individuas e imposições da } \\
\text { organização e da sociedade. }\end{array}$ \\
\hline Motta (2006) & $\begin{array}{l}\text { Uma ocupação ou profissão representada por etapas e possivelmente por uma } \\
\text { progressão. }\end{array}$ \\
\hline Snell e Bohlander (2009) & $\begin{array}{l}\text { Sequência de percepções individuais, atitudes e comportamentos que deixam } \\
\text { transparecer um desenvolvimento e um êxito nas experiências de trabalho e de } \\
\text { vida de uma pessoa. }\end{array}$ \\
\hline Bendassolli (2009) & $\begin{array}{l}\text { Emprego assalariado ou atividade não remunerada; pertencimento a um grupo } \\
\text { profissional ou a manifestação da mais pura idiossincrasia; vocação ou ocupação; } \\
\text { posiça em uma organização ou trajetória de um indivíduo que trabalha por conta } \\
\text { própria; uma fonte de informação para as empresas alocarem recursos. }\end{array}$ \\
\hline
\end{tabular}

Fonte: Elaboração Própria (2017) a partir de Hall (1976 apud DUTRA 2002); Van Maanen (1977 apud DUTRA 2002); London e Stumph (1982 apud DUTRA 2002); Chanlat (1995); Motta (2006); Bendassolli (2009); Snell e Bohlander (2009).

A partir dos anos setenta, surgiram significativas transformações econômicas e sociais que ocasionaram a ampliação do conceito de carreira (BENDASSOLLI, 2009) e, consequentemente, a produção literária mundial que versa sobre esta temática também foi afetada, uma vez que, uma parcela expressiva das produções era voltada para o meio empresarial. A partir da década de oiten- ta, houve a inserção da perspectiva voltada para as pessoas, na autogestão da carreira, ancorada nas mudanças ocorridas no mercado de trabalho que se tornou mais exigente, globalizado e ganhou mais mobilidade. Assim, carreira não é tratada como uma sequência linear de experiências de trabalho e sim como uma série de estágios e transições que vão variar em função das pressões sobre o indiví- 
duo, originadas dele próprio e do ambiente onde está inserido (DUTRA, 2002).

Observa-se que as pessoas estão mais preocupadas em gerir suas carreiras e, por se tratar de um processo que envolve muito planejamento e análise, podem recorrer a um conjunto de ferramentas e técnicas que as ajudem a medir seu potencial. Nessa perspectiva, Snell e Bohlander (2009) elencam ferramentas e técnicas, das quais, cinco estão apresentadas no quadro 03 , a seguir:

\section{QUADRO 03- FERRAMENTAS E TÉCNICAS DE PLANEJAMENTO DE CARREIRA}

\begin{tabular}{|l|l|}
\hline $\begin{array}{l}\text { Workshops de } \\
\text { planejamento de } \\
\text { carreira }\end{array}$ & $\begin{array}{l}\text { Apresentações que auxiliam os indivíduos a gerirem suas próprias carreiras, ajudando } \\
\text { a tomar decisões, estabelecer metas, buscar informações sobre planejamento, entre } \\
\text { outras. }\end{array}$ \\
\hline $\begin{array}{l}\text { Aconselhamento de } \\
\text { carreira }\end{array}$ & $\begin{array}{l}\text { Implica na discussão sobre interesse, metas, habilidades pessoais e objetivos de } \\
\text { desenvolvimento de carreira adequados para cada indivíduo }\end{array}$ \\
\hline $\begin{array}{l}\text { Levantamento } \\
\text { das necessidades } \\
\text { individuais de } \\
\text { desenvolvimento }\end{array}$ & $\begin{array}{l}\text { Ao levar em consideração a escolha da carreira feita por cada indivíduo, considerando } \\
\text { os requisitos e as qualificações necessárias para construí-la, são apontadas as } \\
\text { necessidades de desenvolvimento ou autodesenvolvimento. }\end{array}$ \\
\hline $\begin{array}{l}\text { Treinamento para } \\
\text { autogestão de carreira }\end{array}$ & $\begin{array}{l}\text { São desenvolvidos para engajar os indivíduos na autogestão de suas carreiras. Nesta, } \\
\text { os indivíduos fazem auto avaliação objetivando aumentarem a sua consciência em } \\
\text { relação as suas próprias atitudes e valores de carreira. }\end{array}$ \\
\hline Mentoração & $\begin{array}{l}\text { Processo no qual uma pessoa torna-se mentor de outra pessoa menos experiente. } \\
\text { Nesse sentido, o aprendizado focaliza metas, oportunidades, expectativas, padrões e } \\
\text { assistência na realização do potencial deste segundo indivíduo. }\end{array}$ \\
\hline
\end{tabular}

Fonte: Elaboração própria (2017) a partir de Snell e Bohlander (2009)

Com o objetivo de tornar as pessoas empreendedoras consigo próprias, o planejamento de carreira faz com que as pessoas reflitam sobre o seu desenvolvimento e para isso, existem diversas maneiras pelas quais se pode estruturar uma carreira. No entanto, é necessário estar atento a duas preocupações: formação de uma visão realista, clara e apurada das próprias qualidades, interesses e inclinações pessoais e estabelecer objetivos de carreira e preferências profissionais (LONDON; STUMPH, 1982 apud DUTRA, 2002). Com isso, o planejamento de carreira pode ser entendido como uma projeção do futuro profissional, que neste caso, parte da iniciativa pessoal e deve ser considerado como um processo contínuo ao longo da vida laboral.

Dessa forma, Dutra (2002) define as seis etapas que compõe o planejamento de carreira. São elas: o Autoconhecimento que diz respeito ao uso de técnicas para autoconhecimento e é a etapa mais complexa; o Conhecimento de mercado que demanda a observação do mercado de trabalho - opções, tendências, limitações e alternativas de desenvolvimento profissional -; os Objetivos de carreira é uma reflexão individual sobre o futuro profissional; a Estratégias de carreira é a direção que se adota para o atingimento dos objetivos; o Plano de ação se constitui em um detalhamento de metas de curso prazo, indicadores de sucesso, fatores críticos para o sucesso e uma avaliação dos recursos; por fim faz-se necessário o acompanhamento do plano em um processo contínuo no qual as pessoas passam a avaliar os resultados das estratégias de carreira, para isso, os objetivos ou metas representam um padrão de mensuração essencial.

\section{PERCURSO METODOLÓGICO}

O tema, ainda pouco explorado no curso de Bacharelado em Administração do DCH-I/UNEB, favoreceu a escolha pela abordagem qualitativa, que pode ser caracterizada pela busca da qualidade e dos significados atribuídos aos fatos. Quanto aos objetivos, foi realizada uma pesquisa descritiva. A pesquisa descritiva, de acordo com Triviños (1987) busca conhecer a realidade estudada, descrevendo seus fatos e fenômenos bem como suas características e seus possíveis problemas.

Inicialmente, foi realizada uma revisão de literatura a fim de obter uma bagagem teórica através da 
observação de materiais publicados. Em seguida, efetuou-se uma pesquisa documental que teve como principal fonte o Projeto de Implantação do curso de Bacharelado em Administração do DCH-I/UNEB (1997), a Resolução n ${ }^{\circ} 4$ de 2005 do Conselho Nacional de Educação Superior e o Projeto Pedagógico do curso de Bacharelado em Administração do DCH-I/UNEB (2017). A pesquisa documental é, segundo Gil (2009), aquela que se vale de materiais que não receberam ainda um tratamento analítico, ou que ainda podem ser reelaborados de acordo com os objetos da pesquisa e possui uma fonte diversificada.

Todo esse embasamento teórico foi responsável por nortear a elaboração do instrumento de coleta de dados que se constitui em um questionário com questões abertas e fechadas, direcionado aos 432 (quatrocentos e trinta e dois) alunos matriculados no curso de Bacharelado em Administração do DCH-I/UNEB em 2017.1, segundo o sistema de informações acadêmicas, acessado na Secretaria Geral de Cursos da PROGRAD/UNEB. Nessa configuração, caracteriza-se, portanto, um estudo de caso único, ou seja, realizado em "um ambiente onde se pode verificar a ocorrência do fenômeno em análise" (PIRES et al, 2015, p. 4). O questionário foi estruturado em três eixos de perguntas com objetivos diferentes, porém, relacionados. O primeiro eixo direcionava-se a definição do perfil socioeconômico dos discentes; o segundo eixo buscava informações sobre a escolha do curso e a formação obtida; por fim, o terceiro eixo abordava o planejamento da carreira e as ferramentas utilizadas para realização de tal planejamento.

Com isso, os dados empíricos da pesquisa foram coletados em campo no mês maio de 2017 e o número de respondentes foi definido utilizando-se o critério da acessibilidade: aqueles que aceitaram responder a pesquisa, após a exposição dos objetivos da mesma, ou melhor, trata-se de uma amostra não probabilística, que segundo Marconi (1990), é a seleção onde o objeto de estudo é escolhido a partir da conveniência do pesquisador e dos parâmetros estabelecidos.

Ao final da coleta de dados, foi possível alcançar 170 (cento e setenta) questionários respondidos. Os dados foram tabulados pelo Sphinx 2000 e os resultados obtidos foram tratados com a utilização do método de análise de conteúdo, assim como, os documentos citados anteriormente também foram tratados. A análise de conteúdo é um conjunto de técnicas de análise das comunicações, que utiliza procedimentos sistemáticos que tem como objetivo ultrapassar as incertezas, enriquecer a leitura dos dados e descrever o conteúdo das mensagens. Ou seja, compreender o sentido das comunicações (MOZZATO; GRZYBOVSKI, 2011; BARDIN, 2006).

\section{RESULTADOS OBTIDOS}

Essa seção tem por objetivo apresentar os resultados da pesquisa de campo realizada com os discentes do curso de Bacharelado em Administração do DCH-I/UNEB, sujeitos da pesquisa.

\section{1 CARACTERIZANDO O CURSO DE BACHARELADO EM ADMIINISTRAÇÃO DO DCH-I/UNEB}

A Universidade do Estado da Bahia (UNEB), fundada em 1983 e mantida pelo Governo do Estado por intermédio da Secretaria da Educação (SEC), está presente geograficamente em todas as regiões do Estado, estruturada no sistema multicampi. A capilaridade de sua estrutura e abrangência de suas atividades está diretamente relacionada à missão social que desempenha, possuindo 29 (vinte e nove) Departamentos instalados em 24 (vinte e quatro) campi (UNEB, 2017).

Dentre o significativo número de cursos ofertados pela UNEB, o curso de Bacharelado em Administração está presente em 7 (sete) campi na modalidade presencial e em 1 (um) campus na modalidade semipresencial. O curso de Administração contemplado neste estudo, está vinculado ao Departamento de Ciências Humanas do Campus I da UNEB (DCH-I/UNEB) localizado na capital. Inicialmente, era ofertado na modalidade de Licenciatura, tornando-se Bacharelado em 1997 devido à necessidade de adaptação às mudanças que estavam ocorrendo na estrutura produtiva do Estado e do país naquela época. Sendo assim, o curso tem a finalidade de formar profissionais para conceber, gerir, desenvolver atividades no setor público e privado, capazes de transitar, ou ao menos, dialogar com as diferentes áreas de formação e capacitação do Administrador (UNEB, 1996).

Com a intenção de estabelecer um comparativo entre as dimensões das $\mathrm{C} \& \mathrm{H}$ demandadas dos Administradores descritas pelo MEC e CFA, foi analisado o conteúdo do Projeto Pedagógico do curso de Bacharelado em Administração do DCH-I/UNEB (2017). As convergências e discrepâncias resultantes desta comparação estão apresentadas no quadro 04 : 
QUADRO 04 - COMPARAÇÃO ENTRE AS COMPETÊNCIAS E HABILIDADES DOS ADMINISTRADORES DESCRITAS PELO MEC, CFA E UNEB

\begin{tabular}{|c|c|c|c|}
\hline DIMENSÕES & MEC & CFA & UNEB \\
\hline Ética & Ética e adaptação & Comportamento ético & - \\
\hline $\begin{array}{l}\text { Solução de } \\
\text { Problemas }\end{array}$ & $\begin{array}{l}\text { Reconhecer e definir } \\
\text { problemas }\end{array}$ & $\begin{array}{l}\text { Identificar problemas, formular e } \\
\text { implantar soluções }\end{array}$ & $\begin{array}{l}\text { Desenvolvimento de } \\
\text { instrumentos para a } \\
\text { solução de problemas }\end{array}$ \\
\hline $\begin{array}{l}\text { Raciocínio } \\
\text { Lógico }\end{array}$ & $\begin{array}{l}\text { Raciocínio Lógico, crítico } \\
\text { e analítico }\end{array}$ & Raciocínio Lógico, crítico e analítico & $\begin{array}{l}\text { Raciocínio Lógico, crítico e } \\
\text { analítico }\end{array}$ \\
\hline $\begin{array}{l}\text { Tomada de } \\
\text { decisão }\end{array}$ & Tomada de decisão & $\begin{array}{l}\text { Planejamento, organização, direção } \\
\text { e controle }\end{array}$ & $\begin{array}{l}\text { Identificação de } \\
\text { mecanismos de } \\
\text { planejamento, organização, } \\
\text { monitoramento e avaliação }\end{array}$ \\
\hline Adaptação & $\begin{array}{l}\text { Iniciativa, determinação, } \\
\text { vontade de aprender, } \\
\text { abertura a mudanças }\end{array}$ & Adaptação à transformação & $\begin{array}{l}\text { Habilidade, flexibilidade e } \\
\text { adaptabilidade frente aos } \\
\text { desafios }\end{array}$ \\
\hline $\begin{array}{l}\text { Conhecimentos } \\
\text { Estratégicos }\end{array}$ & Pensamento estratégico & $\begin{array}{l}\text { Conhecimentos específicos para } \\
\text { administração estratégica, finanças/ } \\
\text { orçamentária e a motivação de } \\
\text { pessoas/equipes }\end{array}$ & - \\
\hline $\begin{array}{l}\text { Projetos } \\
\text { [Elaboração e } \\
\text { Gestão] }\end{array}$ & $\begin{array}{l}\text { Capacidade de elaborar, } \\
\text { implementar e consolidar } \\
\text { projetos }\end{array}$ & - & - \\
\hline $\begin{array}{l}\text { Criatividade e } \\
\text { Inovação }\end{array}$ & - & Criatividade e inovação & $\begin{array}{l}\text { Interação Criativa frente } \\
\text { aos diversos contextos } \\
\text { organizacionais e sociais; } \\
\text { gestão inovadora }\end{array}$ \\
\hline Profissionalismo & - & $\begin{array}{l}\text { Comprometimento e } \\
\text { Profissionalismo }\end{array}$ & - \\
\hline $\begin{array}{l}\text { Comunicação e } \\
\text { Negociação }\end{array}$ & $\begin{array}{l}\text { Comunicação e } \\
\text { negociação }\end{array}$ & - & $\begin{array}{l}\text { Desenvolvimento } \\
\text { de processos de } \\
\text { articulação e negociação } \\
\text { interinstitucionais }\end{array}$ \\
\hline $\begin{array}{l}\text { Posicionamento } \\
\text { Gerencial/ } \\
\text { Liderança }\end{array}$ & $\begin{array}{l}\text { Refletir e atuar sobre a } \\
\text { produção, diante de uma } \\
\text { função gerencial }\end{array}$ & Preparo para liderança & - \\
\hline $\begin{array}{l}\text { Formação em } \\
\text { Consultoria }\end{array}$ & $\begin{array}{l}\text { Realizar consultoria em } \\
\text { gestão e administração }\end{array}$ & - & - \\
\hline $\begin{array}{l}\text { Relacionamento } \\
\text { Interpessoal }\end{array}$ & - & Relacionamento interpessoal & $\begin{array}{l}\text { Comunicação interpessoal } \\
\text { e expressões nas relações }\end{array}$ \\
\hline Visão Sistêmica & - & Visão do todo & $\begin{array}{l}\text { Compreensão da } \\
\text { Administração de forma } \\
\text { integrado, sistêmico e } \\
\text { analítico }\end{array}$ \\
\hline
\end{tabular}

Fonte: Elaboração própria a partir de MEC (2005), CFA (2011;2015) e UNEB (2017). 
Ao estabelecer a comparação entre as Competências e Habilidades dos Administradores descritas pelo MEC, CFA e UNEB, observa-se que as dimensões Ética, Projetos [Elaboração e Gestão], Conhecimentos Estratégicos, Profissionalismo, Posicionamento Gerencial/Liderança e Formação em Consultoria não aparecerem contempladas no atual Projeto Pedagógico do Curso. Tomando como referências as dimensões de C\&H apresentadas nos quadros 01 e 04 , pediu-se que os alunos avaliassem, a partir das suas percepções, o seu nível de desenvolvimento em relação as C\&H que estão sendo desenvolvidas ao longo do curso. Para tal, utilizaram uma escala de 1 (um) a 5 (cinco), na qual, 1 representava nenhum desenvolvimento e 5 desenvolvimento satisfatório. Com isso, foi possível levantar que em relação às dimensões Ética, Solução de Problemas, Adaptação, Conhecimentos Estratégicos, Profissionalismo, Posicionamento gerencial/Liderança, Relacionamento Interpessoal e Visão Sistêmica, os respondentes declararam que estão obtendo um desenvolvimento considerável, pois para estas atribuíram nota 4 (quatro). Curiosamente, entre as C\&H que estão sendo desenvolvidas consideravelmente, não aparecem contempladas no projeto: Conhecimentos Estratégicos, Profissionalismo e Posicionamento Gerencial/Liderança.

Em relação às demais dimensões: Raciocínio Lógico, Projetos [Elaboração e Gestão], Criatividade e Formação em Consultoria, os alunos declararam uma posição de neutralidade, ou seja, atribuíram nota 3 (três). Dessa forma, pode-se perceber que apesar das dimensões Raciocínio Lógico e Criatividade estarem sendo levadas em consideração no Projeto Pedagógico do curso, os alunos não têm percepção do desenvolvimento dessas dimensões.

Ao comparar as Competências e Habilidades dos Administradores descritas pelo MEC, CFA E UNEB, observa-se um desalinhamento, que é, inclusive, observado pelos alunos. Faz-se necessário destacar que os conteúdos não observados no Projeto Pedagógico do Curso (PPC) são estruturantes para a formação de administradores. Competências tais como ética, gestão estratégica e liderança, essenciais a atividade gestora, não estão destacadas somente pela IES estudada. O que cabe uma recomendação de revisão do PPC, já que são competências elementares. As demais competências - Projetos, Profissionalismo e Consultoria - apesar de importantes, não demandam uma evidência objetiva, podendo aparecer como conteúdos em distintas disciplinas, o que merece uma análise nos planos de ensino para uma avaliação mais acurada.

\subsection{CARACTERIZANDO OS DISCENTES DO CURSO DE BACHARELADO EM ADMINIS- TRAÇÃO DO DCH-I/UNEB: SEU PERFIL SO- CIOECONÔMICO E PERCEPÇÕES SOBRE ESTRUTURAÇÃO DA CARREIRA}

A partir dos resultados da pesquisa empírica referentes ao primeiro eixo do instrumento de coleta de dados, realizou-se uma análise do perfil socioeconômico dos discentes do curso de Bacharelado em Administração do DCH-I/UNEB. Com relação ao perfil observa-se que a maioria, aproximadamente $60 \%$ dos respondentes, tem até 25 (vinte e cinco anos) com predominância do sexo feminino [54,7\%]. Em relação à cor da pele, a categoria de maior destaque é composta por pessoas que se declararam negras [42,9\%], o que levou à percepção de que a distribuição étnica em relação à desigualdade, no acesso a informação, enquanto um problema social nacional, possui menor impacto na UNEB. Esse fato evidenciado nesta pesquisa, reflete o caráter desta Universidade, uma vez que, através de ações afirmativas como cotas, expande o acesso à informação para essa categoria étnica a fim de diminuir tal desigualdade. Ainda em relação ao perfil, $76,5 \%$ dos pesquisados são naturais de Salvador, com $63,5 \%$ dos respondentes oriundos do Ensino Médio na rede pública. Apesar da predominância de não cotistas [55,3\%], foi possível apurar que 44,7\% dos respondentes se declaram cotistas, o que leva a destacar que o desenvolvimento da política de cotas aderida pela Universidade, vem gerando resultados ao longo dos anos.

Em relação ao mercado de trabalho, a maioria $[55,9 \%]$ dos respondentes declarou estar inserido na modalidade de estágio [39,4\%] e emprego [16,5\%].

A escolha do curso de graduação, como explicitado anteriormente, é baseada em fatores intrínsecos e extrínsecos e, geralmente, marca o início da carreira do indivíduo, podendo estar ou não fazendo parte de um planejamento de carreira. Neste sentido, ao serem questionados sobre qual fator influenciou a escolha do curso de Administração, a maior categoria $[26,5 \%]$, declarou que sua escolha foi baseada na natureza do seu projeto profissional/carreira, seguida da existência de um amplo mercado de trabalho [17,5\%]. Nessa perspectiva, o comportamento dos alunos da UNEB em relação à escolha do curso de Administração vai de encontro ao comportamento dos respondentes das pesquisas realizadas pelo CFA, nos anos de 2011 e 2015, uma vez que, nestas pesquisas não foi 
evidenciada a escolha do curso originada desse fator. Portanto, percebe-se que os discentes de Administração do DCH-I/UNEB, basearam-se, principalmente em fatores intrínsecos para realizarem a escolha da sua carreira.

Quando questionados se Administração foi a primeira opção de curso, 61,2 \% responderam que sim. Aqueles que responderam que não [38,2\%], destacaram que suas primeiras opções estão compreendidas entre Direito [21,3\%], Engenharias $[10,1 \%] \mathrm{e}$, em terceiro lugar, Contabilidade e Medicina com 5,6\% de frequência cada uma. Tendo em consideração a realização de outra graduação antes de iniciarem a graduação em Administração, a maioria [64,7\%] respondeu que nunca realizaram.

Numa escala que partia de insuficientemente informado à suficientemente informado, 55,3\% dos pesquisados afirmaram estar basicamente informado sobre o curso antes do seu ingresso na Universidade e $57,1 \%$ declararam que nunca pensaram em desistir do curso, contrariando Bertero (2006) quando este enuncia que a maioria dos alunos de Administração tem pouca consciência do que seja uma carreira plena de Administrador. Indo além, os respondentes declararam que este conhecimento básico sobre o curso de Administração, em sua maior categoria $[21,2 \%]$, foi adquirido através de uma experiência de trabalho própria.

No que concerne à área de interesse da Administração, predominaram os interesses pelas áreas de Empreendedorismo [17,6\%], Finanças [16,5\%], Pública $[13,5 \%$ ] e Recursos Humanos [13,5\%]. Nesse cenário, os pesquisados atribuíram o seu interesse por essas áreas à afinidade com suas Competências e Habilidades [52,4\%], evidenciando a importância do estabelecimento da carreira com base na percepção individual.

Quanto ao terceiro eixo do questionário, primeiramente, os alunos foram questionados se realizam ou já realizaram algum planejamento de carreira estruturado. Constatou-se que $60,6 \%$ dos respondentes não realizaram e não o realizam. Em relação ao conhecimento sobre ferramentas e técnicas de planejamento de carreira, $65,9 \%$ dos respondentes declararam desconhecê-las, fato este que foi certificado quando procurou-se entender o nível de conhecimento, numa escala em que 1 (um) representava totalmente desconhecido e 5 (cinco) representava totalmente conhecido, em relação as cinco ferramentas e técnicas de planejamento de carreira descritas por Snell e Bohlander (2009), conforme tabela 01, que evidencia que a maior categoria dos respondentes afirmaram desconhecê-las totalmente.

Em seguida, os alunos foram questionados em relação à utilização das técnicas e ferramentas $68,2 \%$ nunca utilizaram Workshops de planejamento de carreira; 65,9\% nunca utilizaram Aconselhamento de carreira; $66,5 \%$ nunca realizaram o levantamento das necessidades individuais de desenvolvimento; 80,6\% nunca participaram de um treinamento para autogestão de carreira; e, 87,1\% nunca utilizaram a Mentoração.

Utilizando-se a mesma escala, buscou-se conhecer o grau de conhecimento sobre as etapas do planejamento de carreira descritas por Dutra (2002). Nesse contexto, averiguou-se também se os respondentes já realizaram ou nunca realizaram as etapas do planejamento de carreira.

Em relação ao grau de conhecimento dos respondentes quanto às etapas do planejamento de carreira, pode-se afirmar que em relação às quatro primeiras etapas - buscar autoconhecimento; buscar conhecimento do mercado; traçar objetivos de carreira; e estabelecer estratégias de carreira - os respondentes demonstraram conhecimento satisfatório [entre 25 e 30\% com avaliação 3 e 4]. Porém, em relação às duas últimas - construir um plano de ação e acompanhar o plano de ação - afirmaram desconhecer totalmente [avaliação 1]. No tocante à realização de cada uma dessas etapas, obteve-se as seguintes respostas: $58,8 \%$ já realizaram a busca pelo autoconhecimento, $65,3 \%$ realizam a busca por conhecimento do mercado de trabalho e $44,5 \%$ já traçaram objetivos de carreira, no entanto, $44,1 \%$ nunca estabeleceram estratégias para alcançar os objetivos de carreira, 59,4\% nunca construíram um plano de ação e, consequentemente, $67,6 \%$ nunca realizaram o acompanhamento do plano de ação.

Por fim, os alunos foram questionados se acreditavam que o planejamento de carreira auxilia significativamente na obtenção do sucesso profissional. Obteve-se 167 respostas para essa questão e 162 [95,3\%] alunos disseram que acreditam. Contudo, percebeu-se que apesar da importância que eles atribuem ao planejamento de carreira para obtenção do sucesso profissional, a maioria não o realiza $[60,6 \%]$ e nem conhece $[65,9 \%]$ as ferramentas e técnicas para realizar um planejamento de carreira consciente. Essa percepção valida a fala de Dutra (2002) quando este declara que a discussão sobre carreira ainda é muito restrita no Brasil, tanto no âmbito da academia, quanto no âmbito das organizações. 
As progressivas transformações sociais, políticas e econômicas têm afetado o mundo do trabalho nos dias atuais e, principalmente, tornado voláteis as relações de trabalho. Uma das consequências dessa dinâmica é a elevação das taxas de desemprego que cria um ambiente de incerteza e instabilidade, em relação ao mercado de trabalho, que por sua vez, tem posto fim nas carreiras sólidas e perenes. Com isso, observa-se entre muitos aspectos, a cobrança pelo protagonismo das pessoas em relação à realização de um planejamento de carreira consciente, para que dessa forma, possam ingressar e aumentar as chances de perpetuação no mercado de trabalho. Neste cenário, esta investigação teve por objetivo verificar a existência do planejamento de carreira, destacando os fatores que influenciam os discentes do DCH-I/UNEB, do curso de Administração, a optarem pela carreira de Administrador.

Ao buscar caracterizar o curso de Bacharelado em Administração do DCH-I/UNEB, verificou-se que: este curso foi concebido em 1997, devido à necessidade de adaptação às mudanças que estavam ocorrendo na estrutura produtiva do Estado e do país. Assim sendo, possui a finalidade de formar profissionais para conceber, gerir, desenvolver atividades no setor público e privado, capazes de transitar, ou ao menos, dialogar com as diferentes áreas de formação e capacitação do Administrador. Ao longo dos 20 (vinte) anos de existência, atravessou significativas transformações que atingiram a Universidade, a exemplo da política de cotas para afrodescendentes. Funcionando nos turnos diurno e noturno, já formou, aproximadamente, 800 (oitocentos) Administradores. Além disso, o curso apresenta considerável conformidade no que tange as Competências e Habilidades dos Administradores apresentadas pelo MEC e CFA.

Em relação ao perfil socioeconômico dos discentes pesquisados, os resultados obtidos permitiram estabelecer o seguinte perfil: possui entre 21 e 26 anos, a cor da pele é negra, pertence ao sexo feminino, são solteiras, de origem ou naturalidade de Salvador/BA, os pais possuem segundo grau completo, possui renda mensal de 2 a 4 salários mínimos. Em relação à rede de Ensino onde cursaram o Ensino Médio, a maioria corresponde à rede pública, não fizeram curso pré-vestibular, ingressaram na Universidade através do vestibular, não são cotistas e, atualmente, se inserem no mercado de trabalho por meio de estágio, seguida de emprego em empresa privada.

Com o intuito de identificar os fatores que influenciaram a escolha do curso Administração e da
UNEB, como instituição formadora, constatou-se que: Administração foi a primeira opção de curso dos discentes; a escolha dos discentes pelo curso de Administração do DCH-I/UNEB foi baseada na natureza do seu projeto profissional/carreira; os discentes não realizaram vestibular em outra IES; escolheram a UNEB por se tratar de uma IES pública; estavam basicamente informados sobre o curso de Administração e a fonte que mais contribuiu para esse básico conhecimento foi a experiência de trabalho própria; as áreas da Administração de maior interesse dos discentes são Empreendedorismo, Finanças, Pública e Recursos Humanos e eles atribuem tal interesse à afinidade com suas Competências e Habilidades.

Ao analisar a percepção dos discentes em relação planejamento de carreira, incluindo o uso de ferramentas para tal, verificou-se que a maioria dos discentes não realizam ou realizaram um planejamento de carreira estruturado. Além disso, afirmaram não conhecer nenhuma ferramenta ou técnica de planejamento de carreira. Essa afirmação foi constatada ao verificar que a maioria dos alunos desconheciam totalmente as cinco ferramentas e técnicas de planejamento de carreira que foram apresentadas e, consequentemente, a maioria também nunca as tinham utilizado. Em relação às etapas do planejamento de carreira, os discentes conhecem consideravelmente as etapas: autoconhecimento, busca pelo conhecimento de mercado, definição de objetivos e de estratégias para alcançá-los, porém, desconhecem a confecção dos planos de ação e do acompanhamento dos mesmos. Por conseguinte, observou-se que os alunos já realizaram as três primeiras etapas e nunca realizaram as três seguintes.

No que se refere às projeções futuras para a consolidação da carreira escolhida, averiguou-se a seguinte posição dos alunos: a maioria pretende realizar uma pós-graduação latu-sensu (especialização) nas áreas Financeira, Marketing e Recursos Humanos.

Por fim, foi evidenciada, através da última pergunta, a importância que os alunos conferem ao planejamento de carreira, uma vez que acreditam que tal planejamento auxilia, significativamente, a obtenção do sucesso profissional. Portanto, recomenda-se que o curso de Bacharelado em Administração estudado, possa incentivar a discussão e ações sobre o planejamento de carreira, a fim de oferecer aos discentes aparatos teóricos e metodológicos para a estruturação consciente de suas carreiras.

Quanto às limitações da pesquisa, a principal diz respeito ao instrumento de coleta de dados. O questio- 
nário aplicado possuía uma grande dimensão e a disposição das perguntas confundiu uma significada parte dos respondentes. Além disso, apresentou questões de difícil compreensão para os respondentes, fato que em algumas questões levou a não resposta dos alunos. Essa limitação poderia ter sido evitada caso tivesse sido realizado o pré-teste do instrumento. No entanto, é possível afirmar que a existência dessa limitação, não prejudicou o alcance dos objetivos desta pesquisa.

Ao final desse trabalho pode-se apontar três sugestões para estudos futuros. A primeira seria realizar uma análise da matriz curricular do curso estudado em relação à sua capacidade de potencializar a carreira dos estudantes, dado que se trata de uma matriz que em seus últimos semestres permite uma flexibilidade e um atendimento às especificidade regionais, o que poderia, se bem utilizado, favorecer o desenvolvimento das diferentes vertentes de carreira possíveis em Administração, tais como: Gestão Pública, Gestão de eventos, Gestão Hospitalar, Gestão
Cultural, dentre outras. A segunda seria dar continuidade a esse estudo, buscando analisar como esse fenômeno ocorre nos cursos de Administração dos diferentes campi da UNEB, a fim de verificar pontos de aproximação e distanciamento no que diz respeito ao direcionamento das carreiras dos alunos dadas as especificidades regionais. Por fim, esse estudo pode ser implementado em outras IES que ofereçam o curso de Administração, tendo, em etapas futuras, a possibilidade de fazer estudos comparativos em relação aos aspectos dos projetos pedagógicos dos cursos, quanto ao desenvolvimento de Competências e Habilidades, verificando qual o melhor modelo da região metropolitana de Salvador que favorece o desenvolvimento das carreiras dos discentes. Sendo assim, seria também importante estudar esse mesmo processo a partir da visão dos egressos, uma vez que, pressupõe-se que estes já estão inseridos no mercado de trabalho, verificando a contribuição dos diferentes cursos para a efetividade das suas carreiras.

\section{REFERÊNCIAS}

AKTOUF, O. Ensino de Administração: por uma Pedagogia para a Mudança. Revista Organizações e Sociedade. v.12, n. 35, outubro/dezembro, 2005.

BARDIN, L. Análise de conteúdo. Lisboa: Edições 70, 2006.

BATISTA-DOS-SANTOS, A, C; OLIVEIRA, J, A. Concepções de administração e administrador em tempos de capitalismo flexível: uma abordagem crítica. Cad.EBAPE.BR. Rio de Janeiro, v.13, n.4 Jan./Mar.2015. p. 52-82. Disponível em: < http://www.scielo.br/pdf/cebape/v13n1/1679-3951-cebape-13-01-00052.pdf >. Acesso em: 02 mar. 2017.

BENDASSOLLI, P. F. Recomposição da relação sujeito-trabalho nos modelos emergentes de carreira. Revista de Administração de Empresas, São Paulo, v.49, n.4, p. 387-400 out./dez. 2009.

BERTERO, Carlos Osmar. Ensino e pesquisa em Administração. São Paulo: Thomson Learning, 2006.

BRASIL. Lei 4.769 de 09 de setembro de 1965. Dispõe sobre o exercício da profissão de Administrador e dá outras providências. Presidência da República, Casa Civil, Subchefia para assuntos jurídicos. Disponível em: $<$ http://www.planalto.gov.br/ccivil_03/leis/14769.htm>. Acesso em: 02 abr. 2017.

Conselho Nacional de Educação. Resolução n.4, de 13 de julho de 2005. Institui as Diretrizes Curriculares Nacionais de Curso de Graduação em Administração, bacharelado, e dá outras providências. Diário Oficial da União, Brasília, 19 de julho de 2005, Seção 1, p.26.

CHANLAT, Jean-François. Quais carreiras e para qual sociedade? (I). Revista de Administração de Empresas, São Paulo, v. 35. n. 6, p. 67-75, nov/dez, 1995. 
CONSELHO FEDERAL DE ADMINISTRAÇÃO (CFA). Pesquisa Nacional Sistema CFA e CRAs. Disponível em: < http://www.cfa.org.br/servicos/publicacoes/pesquisa-perfil-2011.pdf> Acesso em: 12 abr. 2017.

COVRE, M.L.M. A formação e a ideologia do administrador de empresa. Petrópolis: Vozes, 1982.

DUTRA, Joel de Souza. As pessoas na organização. 15 ed. São Paulo: Gente, 2002.

GIL, A. C. Como elaborar projetos de pesquisa. 4. ed. São Paulo: Atlas, 2009. p. 45-46.

GURGEL, C. Administração Pública. Disponível em: <http://www.otal.ifcs.ufrj.br/wp-content/uploads/2013/10/Gurgel.pdf>. Acesso em: 2 mar. 2017.

INSTITUTO ETHOS DE EMPRESAS E RESPONSABILIDADE SOCIAL. Perfil social, racial e de gênero das 500 maiores empresas do Brasil e suas ações afirmativas. Disponível em: $<$ https://issuu.com/institutoethos/docs/perfil_social_tacial_genero_500empr> Acesso em: 14 mai. 2017.

INSTITUTO NACIONAL DE ESTUDOS E PESQUISAS EDUCACIONAIS ANÍSIO TEIXEIRA. Censo da Educação Superior. Disponível em: <http://download.inep.gov.br/educacao_superior/censo_superior/apresentacao/2014/coletiva_censo_superior_2013.pdf> Acesso em: 14 mai. 2017.

KWASNICKA, E. L. Introdução à Administração. São Paulo, Atlas, 1980.

MARCONI, M. A. Técnicas de pesquisa: planejamento e execução de pesquisas, amostras e técnicas de pesquisa, elaboração, análise e interpretação de dados. - São Paulo: Atlas, 1990.

MOTTA, P.R. Reflexões sobre a customização das carreiras gerenciais: a individualidade e a competitividade contemporânea. In: BALASSIANO, M.; COSTA, I.S.A.C. Gestão de carreiras: dilemas e perspectivas. São Paulo: Atlas. 2006, p. 9-19.

MOZZATO, Anelise Rebelato; GRZYBOVSKI; Denize. Análise de conteúdo como técnica de Análise de Dados Qualitativos no Campo da Administração: Potencial e Desafios. Disponível em: $<$ http://www.scielo. br/pdf/rac/v15n4/a10v15n4.pdf>. Acesso em: 15 mar. 2017.

OLIVEIRA, M, C; GUimarÃES, V, F; COLETA, M, F, D. Modelo Desenvolvimentista de Avaliação e Orientação de Carreira Proposto por Donald Super. Revista Brasileira de Orientação Profissional. v.7, n.2, p. 11-18, 2006.

PIRES, R, C. et al. A Prática Profissional dos Egressos do Curso de Administração do DCH-I/UNEB: subsídio para reestruturação curricular. In: Simpósio Avaliação da Educação Superior - AVALIES, 2015, Porto Alegre.

SNELL, S, A; BOHLANDER, G, W. Administração de Recursos Humanos. São Paulo : Cengage Learning , 2011.

TRIVIÑOS, A. N. S. Introdução à pesquisa em ciências sociais: a pesquisa qualitativa em educação. São Paulo: Atlas, 1987. p.133.

UNEB. Projeto para implantação do curso de Administração. UNEB/PROGRAD, CETEBA: Salvador, 1996.

. Projeto Pedagógico do Curso de Bacharelado em Administração do DCH-I/UNEB. UNEB/PRO-

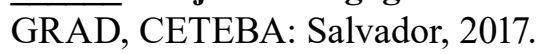

